\title{
A retrospective study on the impact of the number of resected lymph nodes on the survival outcome of stage IV rectal cancer patients after preoperative therapy
}

\author{
Kexiang $\mathrm{Xi}^{1 *}$, Hui $\mathbf{Y u}^{2,3 \#}$, Kexing $\mathbf{X i}^{4}$ \\ ${ }^{1}$ Department of Obstetrics, Jieyang People's Hospital, Jieyang, China; ${ }^{2}$ State Key Laboratory of Oncology in South China, Collaborative Innovation \\ Center for Cancer Medicine, Guangzhou, China; ${ }^{3}$ Department of Thoracic Surgery, Sun Yat-sen University Cancer Center, Guangzhou, China; \\ ${ }^{4}$ State Key Laboratory of Oncology in South China, Collaborative Innovation Center for Cancer Medicine, Sun Yat-sen University Cancer Center, \\ Guangzhou, China \\ Contributions: (I) Conception and design: K Xi, K Xi; (II) Administrative support: K Xi, H Yu; (III) Provision of study materials or patients: All \\ authors; (IV) Collection and assembly of data: K Xi, H Yu; (V) Data analysis and interpretation: All authors; (VI) Manuscript writing: All authors; (VII) \\ Final approval of manuscript: All authors. \\ "These authors contributed equally to this work. \\ Correspondence to: Kexing Xi. State Key Laboratory of Oncology in South China, Sun Yat-sen University Cancer Center, No. 651 Dongfeng Road \\ East, Guangzhou 510060, China. Email: xi_kexing@163.com.
}

Background: There is no consensus on the optimal number of examined LNs for stage IV rectal cancer patients after preoperative therapy. We aimed to explore the impact of the number of resected lymph nodes (LNs) on the survival outcomes of stage IV rectal cancer patients after preoperative therapy.

Methods: Clinicopathologic data of 556 patients diagnosed with stage IV rectal cancer between 1st January, 2010 and 31st December, 2015 from the Surveillance, Epidemiology, and End Results (SEER) database after preoperative therapy were reviewed. The patients were further divided into two groups: the $\geq 15$ resected LNs group and $<15$ resected LNs group based on the X-tile software analysis results of the number of resected LNs.

Results: Both univariate and multivariate regression analyses revealed that the number of resected LNs and $\mathrm{N}$ status were significantly positively correlated with the survival outcome of the patients. Patients in the $\geq 15$ resected LNs group had a significant better cancer-specific survival (CSS) ( $\mathrm{P}=0.003)$ than those in the $<15$ resected LNs group. The 3 -year CSS rate was $63.2 \%$ for patients with $\geq 15$ resected LNs compared with $55.7 \%$ for those with $<15$ resected LNs. The 5 -year CSS rate was $50.2 \%$ and $30.5 \%$ for patients in the $\geq 15$ resected LNs group and those in the $<15$ resected LNs group, respectively.

Conclusions: The number of resected LNs is an important independent prognostic factor that influences the survival outcome of stage IV rectal cancer patients after receiving preoperative therapy.

Keywords: Rectal cancer; number of resected lymph nodes; stage IV; Survival, Surveillance, Epidemiology, and End Results database (SEER database)

Submitted Mar 31, 2020. Accepted for publication Jul 31, 2020.

doi: 10.21037/jgo-20-175

View this article at: http://dx.doi.org/10.21037/jgo-20-175

(C) Journal of Gastrointestinal Oncology. All rights reserved. 


\section{Introduction}

Colorectal cancer is one of the most common cancers in the world based on GLOBOCAN 2018 estimates. Approximately 1.8 million new cases of colorectal cancer are diagnosed yearly (1). The increasing incidence of rectal cancer cases have raised huge concerns within the scientific and health experts. Based on the guidelines of the American Joint Committee on Cancer (AJCC) and the National Comprehensive Cancer Network $(\mathrm{NCCN})$, patients diagnosed with locally advanced rectal cancer (T3/4 or N1/2) should receive neoadjuvant chemoradiotherapy (NCRT) follow by total mesorectal excision (TME) thereafter $(2,3)$. These guidelines suggest that a minimum of 12 lymph nodes (LNs) should be examined for rectal cancer patients regardless of neoadjuvant therapy $(4,5)$. However, several studies report that neoadjuvant chemoradiotherapy decrease the number of LNs retrieved in subsequent surgery resections (6-8). This further disputes the optimal number of examined LNs in rectal cancer patients after neoadjuvant therapy $(9,10)$.

The LN status is an important factor in staging and survival of rectal cancer patients (2). The number of resected LNs is significantly associated with the survival outcome of rectal cancer patients and is thus vital for accurate $\mathrm{pN}$ staging (11-14). Several studies have postulated that the higher the number of LNs recovered, the higher the number of LNs metastases is in colorectal cancer $(15,16)$. This largely depend on the criterion of lymphadenectomy used by clinicians. To date, there is no consensus on the optimal number of examined LNs for rectal cancer patients after preoperative therapy.

In clinical practice, some rectal cancer patients receive preoperative therapy followed by TME are confirmed to have stage IV rectal cancer after postoperative pathological diagnosis. For these patients, the standard number of examined LNs suitable for them remains unclear. As such, this study aimed to explore the impact of the number of resected LNs on the survival of stage IV rectal cancer patients who initially received preoperative therapy. Rectal cancer datasets from the Surveillance, Epidemiology, and End Results (SEER) database were used. We present the following article in accordance with the STROBE reporting checklist (available at http://dx.doi. org/10.21037/jgo-20-175).

\section{Methods}

\section{Patient selection}

Clinical data of patients diagnosed with stage IV rectal cancer after preoperative radiotherapy between 1 st January, 2010 and 31st December, 2015 was retrospectively examined. Patients whose TNM stage information was incomplete as well as those whose radiation method was not beam radiation or unknown were excluded from the study. Patients whose data of examined LNs was unclear or incomplete and those with a second cancer or borderline tumor were also excluded. This was also the case for patients less than 18 years old, patients without chemotherapy, non-adenocarcinoma patients, patients with tumor deposit and patients who died within 30 days after surgery. In addition, patients with no surgical procedure of primary site and or the information of surgery was incomplete as well as those died not due to the cancer were also excluded from the study. Finally, 556 patients were enrolled in the study (Figure 1).

\section{Statistical analysis}

The optimal cutoff points of the number of resected LNs were defined using the $\mathrm{X}$-tile software version 3.6.1 (Copyright Yale University 2003). The chi-square test was used to calculate differences in distribution for categorical variables. Moreover, the Kaplan-Meier method was employed to determine the prognostic factors of cancerspecific survival (CSS) using the log-rank test. In the same line, cox univariate and multivariate analyses were used to identify the most significant prognostic factors of CSS. All the statistical analyses were carried out using SPSS software, v25.0 (SPSS Inc., Chicago, IL, USA). A P value less than 0.05 indicated that there were significant differences between groups.

The study was conducted in accordance with the Declaration of Helsinki (as revised in 2013). The data in 


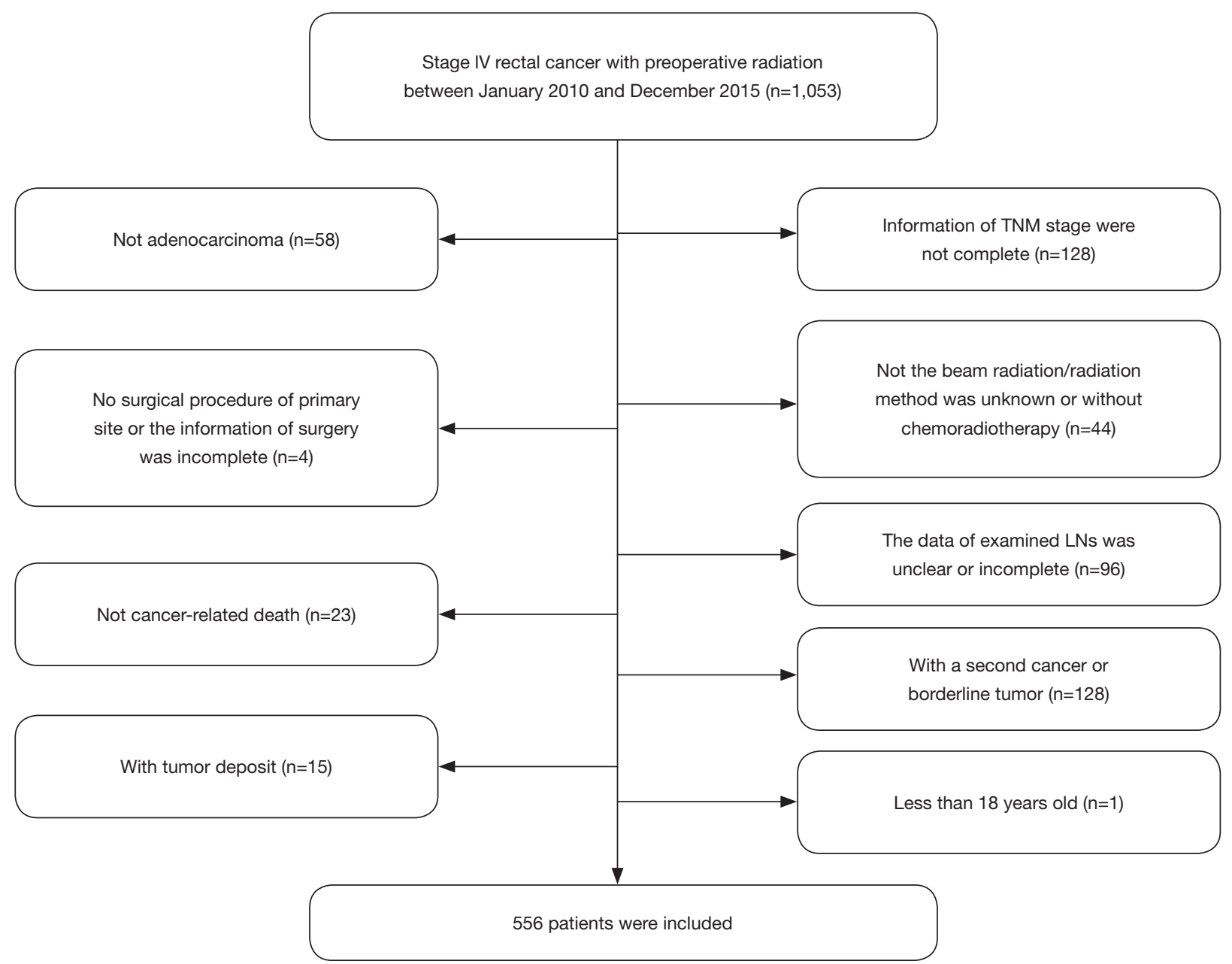

Figure 1 Flow chart for screening enrolled patients.

the SEER database were publicly available and de-identified thereby no ethics approval was required.

\section{Results}

\section{Patient characteristics}

A total of 556 patients were enrolled in the study. The optimum cutoff values of the number of resected LNs were less than $15(<15)$ and more than or equal to $15(\geq 15)$ based on the $\mathrm{X}$-tile analysis results (Figure 2). The correlation between patient characteristics and the number of resected LNs is shown in Table $1 . \mathrm{N}$ status was significantly associated with the number of resected LNs. However, age, gender, race, marital status, grade, tumor size, CEA level, perineural invasion, $\mathrm{T}$ status, and metastatic location were not associated with the number of resected LNs.
The distribution of the number of resected LNs in 556 patients is shown in Figure 3. The mean and the median number of resected LNs was 14.9 and 14.0, respectively (Table 2).

\section{Survival outcomes based on the number of resected LNs}

Kaplan-Meier survival analysis and log-rank comparison results revealed that the $\geq 15$ resected LNs group had a significant better CSS $(\mathrm{P}=0.003)$ compared to the $<15$ resected LNs group. The 3 -year CSS rate was $63.2 \%$ for patients with $\geq 15$ resected LNs compared with $55.7 \%$ for those with $<15$ resected LNs. The 5 -year CSS rate was $50.2 \%$ and $30.5 \%$ for patients in the $\geq 15$ resected $\mathrm{LNs}$ group and those in the $<15$ resected LNs group, respectively (Figure 4). 

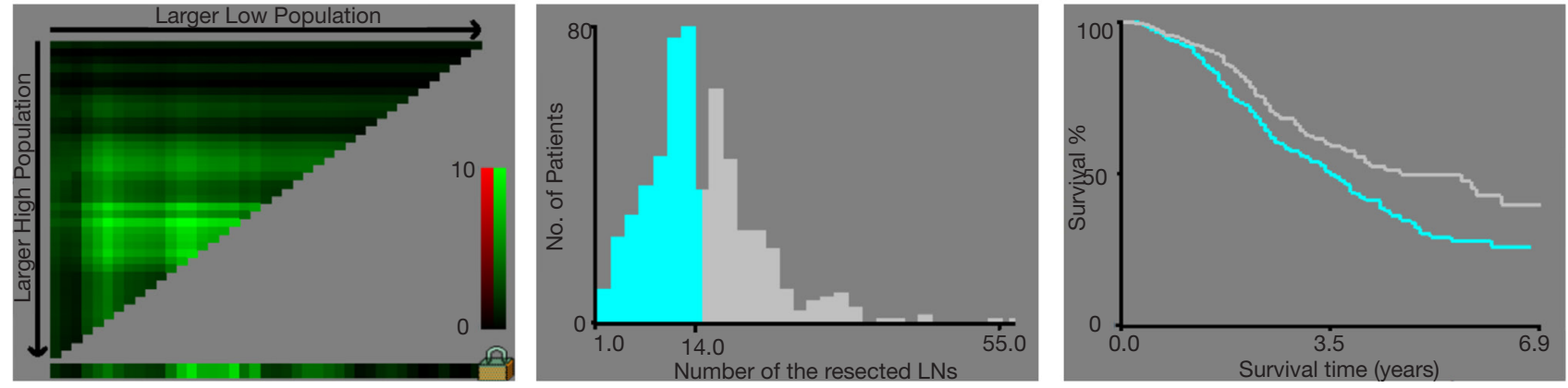

Figure $2 \mathrm{X}$-tile analysis to determine the cutoff values of the number of resected LNs.

Table 1 Distribution of clinicopathologic characteristics between the two groups (grouped by the number of resected LNs)

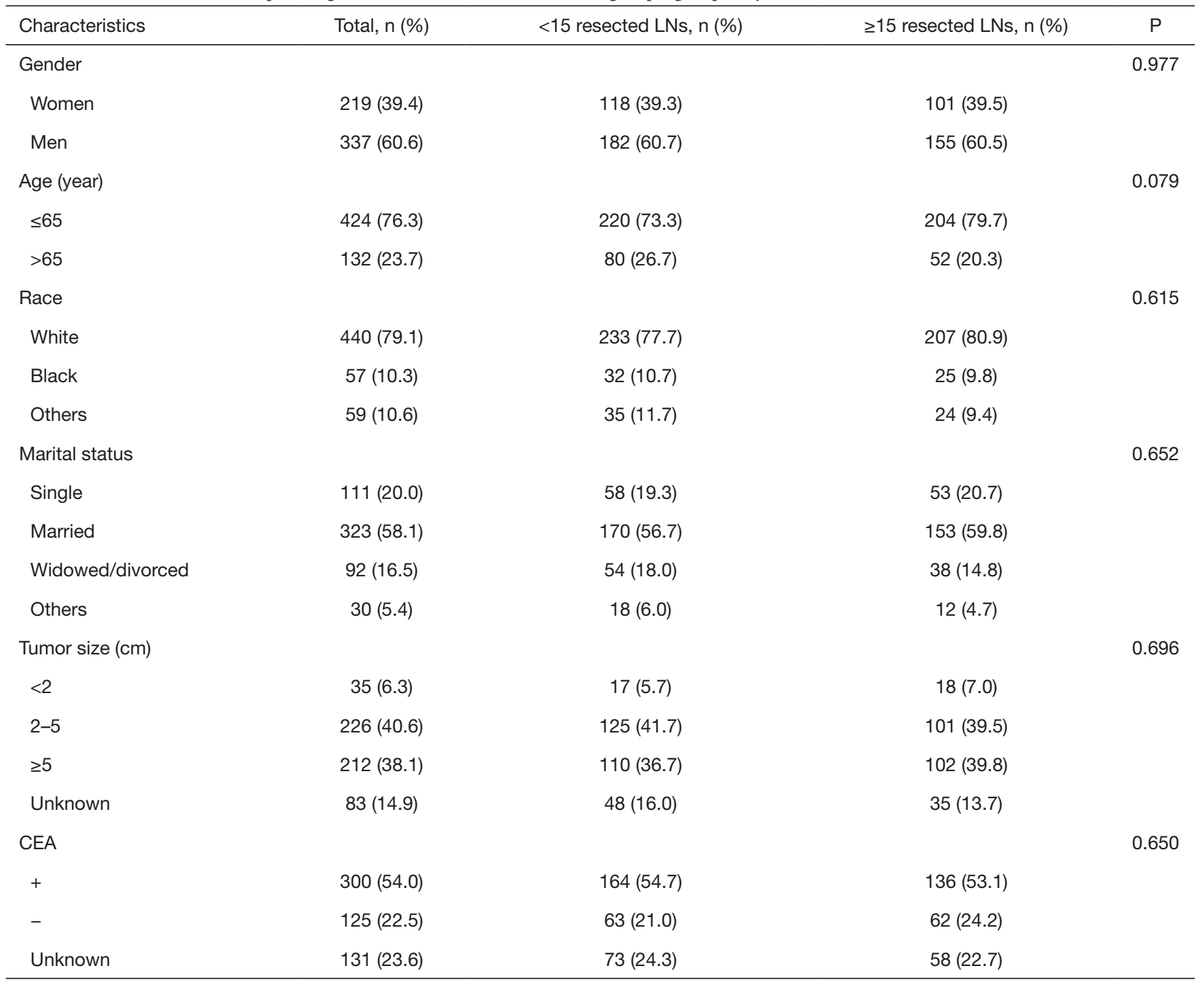

Table 1 (continued) 
Table 1 (continued)

\begin{tabular}{|c|c|c|c|c|}
\hline Characteristics & Total, n (\%) & $<15$ resected LNs, $\mathrm{n}(\%)$ & $\geq 15$ resected LNs, n (\%) & $\mathrm{P}$ \\
\hline Well/moderate & $400(71.9)$ & $211(70.3)$ & $189(73.8)$ & \\
\hline Poor/undifferentiated & $95(17.1)$ & $51(17.0)$ & $44(17.2)$ & \\
\hline Unknown & $61(11.0)$ & $38(12.7)$ & $23(9.0)$ & \\
\hline- & $342(61.5)$ & $178(59.3)$ & $164(64.1)$ & \\
\hline+ & $139(25.0)$ & $83(27.7)$ & $56(21.9)$ & \\
\hline Unknown & $75(13.5)$ & $39(13.0)$ & $36(14.1)$ & \\
\hline T status & & & & 0.990 \\
\hline T3 & $413(74.3)$ & $224(74.7)$ & $189(73.8)$ & \\
\hline T4 & $95(17.1)$ & $51(17.0)$ & $44(17.2)$ & \\
\hline $\mathrm{N}$ status & & & & 0.003 \\
\hline No & $200(36.0)$ & $122(40.7)$ & $78(30.5)$ & \\
\hline $\mathrm{N} 1$ & $210(37.8)$ & $116(38.7)$ & $94(36.7)$ & \\
\hline N2 & $146(26.3)$ & $62(20.7)$ & $84(32.8)$ & \\
\hline Metastatic location & & & & 0.967 \\
\hline Liver & $315(56.7)$ & $170(56.7)$ & $145(56.6)$ & \\
\hline
\end{tabular}

LNs, lymph nodes.

Cox univariate regression analysis revealed that grade, perineural invasion, $\mathrm{N}$ status, and number of resected LNs (the cutoff value was 15 ) were significantly associated with CSS (P values were 0.002, <0.001, <0.001, 0.003, respectively). However, gender, age, race, marital status, tumor size, CEA level, T status, number of resected LNs (the cutoff value was 12), and metastatic location were not correlated with CSS. Similarly, cox multivariate regression analysis revealed that grade, perineural invasion, $\mathrm{N}$ status, and number of resected LNs (the cutoff value was 15) were significantly positively correlated with CSS (P values were
$0.006,0.017,<0.001,<0.001$, respectively) (Table 3).

\section{Discussion}

The National Comprehensive Cancer Network (NCCN) recommend that 12 or more LNs should be retrieved for rectal cancer staging. However, many studies have postulated that preoperative chemoradiotherapy reduce the number of LNs examined from the rectal carcinoma specimens $(17,18)$. To date, there is no consensus on an absolute number of LNs that should be recovered for rectal 


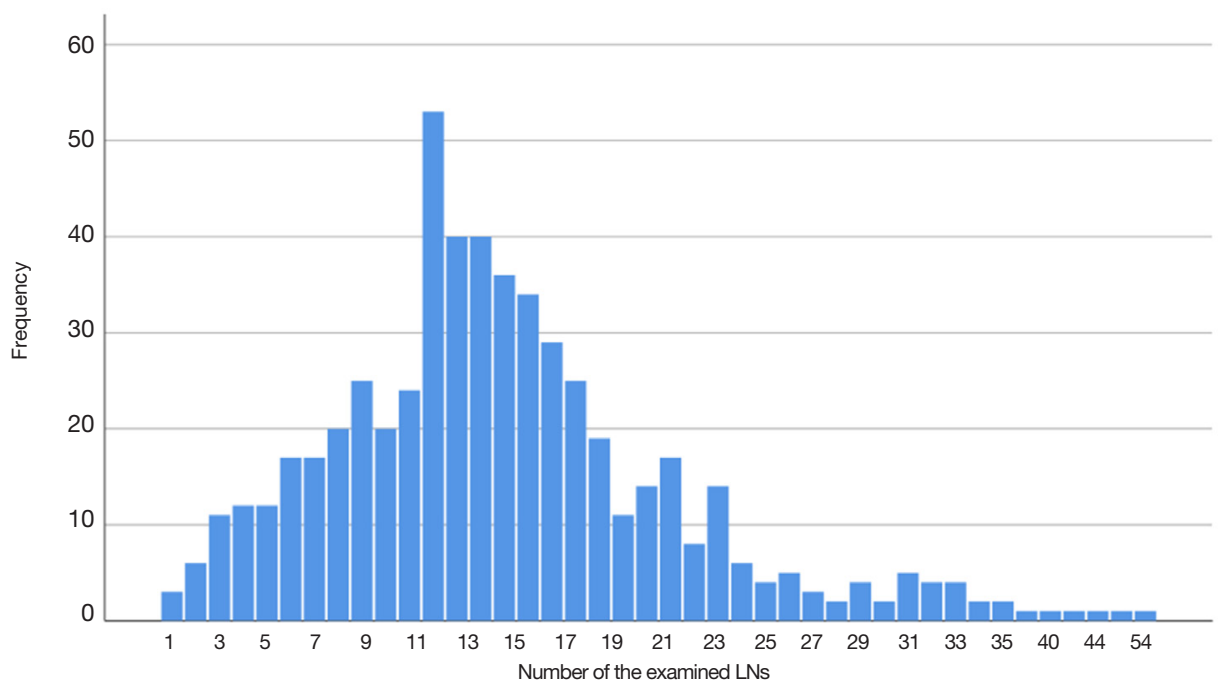

Figure 3 Distribution of the number of resected LNs in 556 patients with stage IV rectal cancer.

Table 2 Characteristics of examined LNs

\begin{tabular}{lcccc}
\hline Characteristics & Mean & Median & Range & Number of patients, $\mathrm{n}(\%)$ \\
\hline Total number of LNs examined & 14.9 & 14.0 & $1-55$ & $556(100.0)$ \\
$<15$ LNs & 9.81 & 11.0 & $1-14$ & $300(54.0)$ \\
$\geq 15$ LNs & 20.9 & 19.0 & $15-55$ & $256(46.0)$ \\
$<12$ LNs & 7.34 & 8.0 & $1-11$ & $167(30.0)$ \\
$\geq 12$ LNs & 18.2 & 16.0 & $12-55$ & $389(70.0)$
\end{tabular}

LNs, lymph nodes.

cancer patients with NCRT. Previous studies postulated that the optimal number of LNs to be examined in rectal cancer patients who receive preoperative chemoradiotherapy range between 7 and 30 LNs (19-21).

In clinical practice, some rectal cancer patients (special group) who receive preoperative chemoradiotherapy followed by TME are confirmed to have stage IV rectal cancer after postoperative pathological diagnosis. Few studies have explored the prognostic role of the number of LNs examined in these patients. Herein, 556 patients with stage IV rectal cancer patients who received preoperative therapy were specially studied to explore the impact of the number of resected LNs on survival. $\mathrm{N}$ status were found to influence the number of LNs resected. When the patients were divided into two groups ( $\geq 15$ resected LNs group and $<15$ resected LNs group), patients in the $\geq 15$ resected LNs group had a significant better CSS than those in the $<15$ resected LNs group. However, the survival outcome between the $\geq 12$ resected LNs group and the $<12$ resected LNs group was not significantly different. These results suggested that the current standard ( $\geq 12$ LNs should be resected) might not be suitable for patients of the special group. In this group, more LNs than the current standard should be examined. Moreover, the $\mathrm{N}$ status was found to be significantly positively correlated with the survival outcome. Patients with N1 or N2 lymph node metastases had a poorer survival outcome compared with those with N0. These results proved that the LN status was still an important prognostic factor for stage IV rectal cancer patients after receiving preoperative therapy.

Cox univariate regression analysis further revealed that there was no association between metastatic location and CSS. This might be attributed to missing or unclear therapy data such as the number and size of metastatic tumors in SEER database thereby leading to bias.

Further to this, lymphadenectomy was found to be 


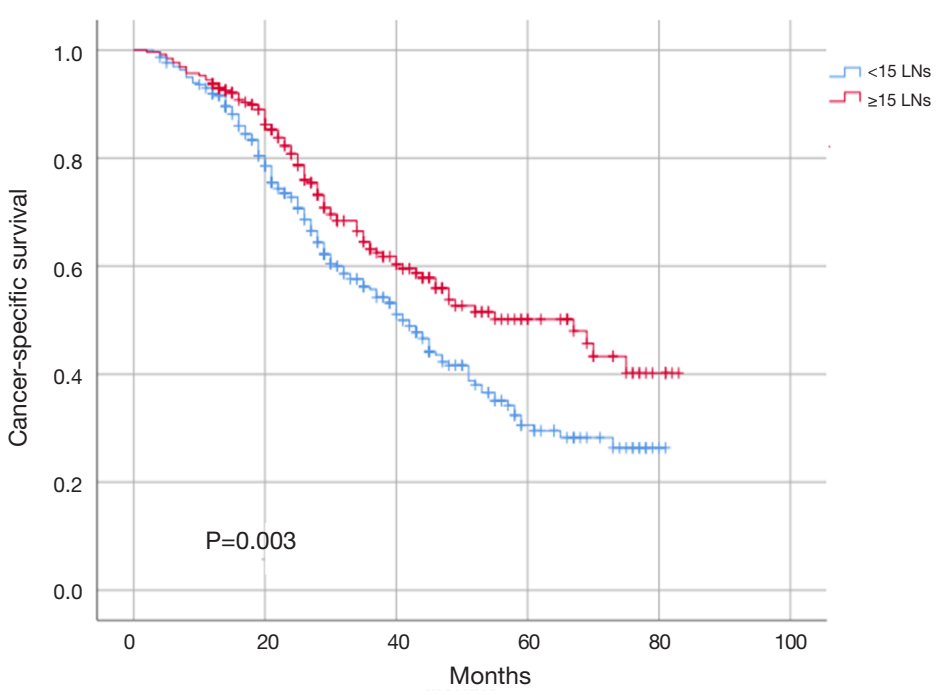

Number at risk

\begin{tabular}{|llllll|}
\hline Months & 0 & 20 & 40 & 60 & 80 \\
\hline \multicolumn{7}{c}{ Number at risk } \\
\hline$<15$ resected LNs & 300 & 215 & 101 & 30 & 3 \\
$\geq 15$ resected LNs & 256 & 193 & 84 & 31 & 6 \\
\hline
\end{tabular}

Figure 4 Cancer-specific survival curves for 556 patients with stage IV rectal cancer.

Table 3 Univariate and multivariate Cox regression analyses results for cancer-specific survival of the 556 patients

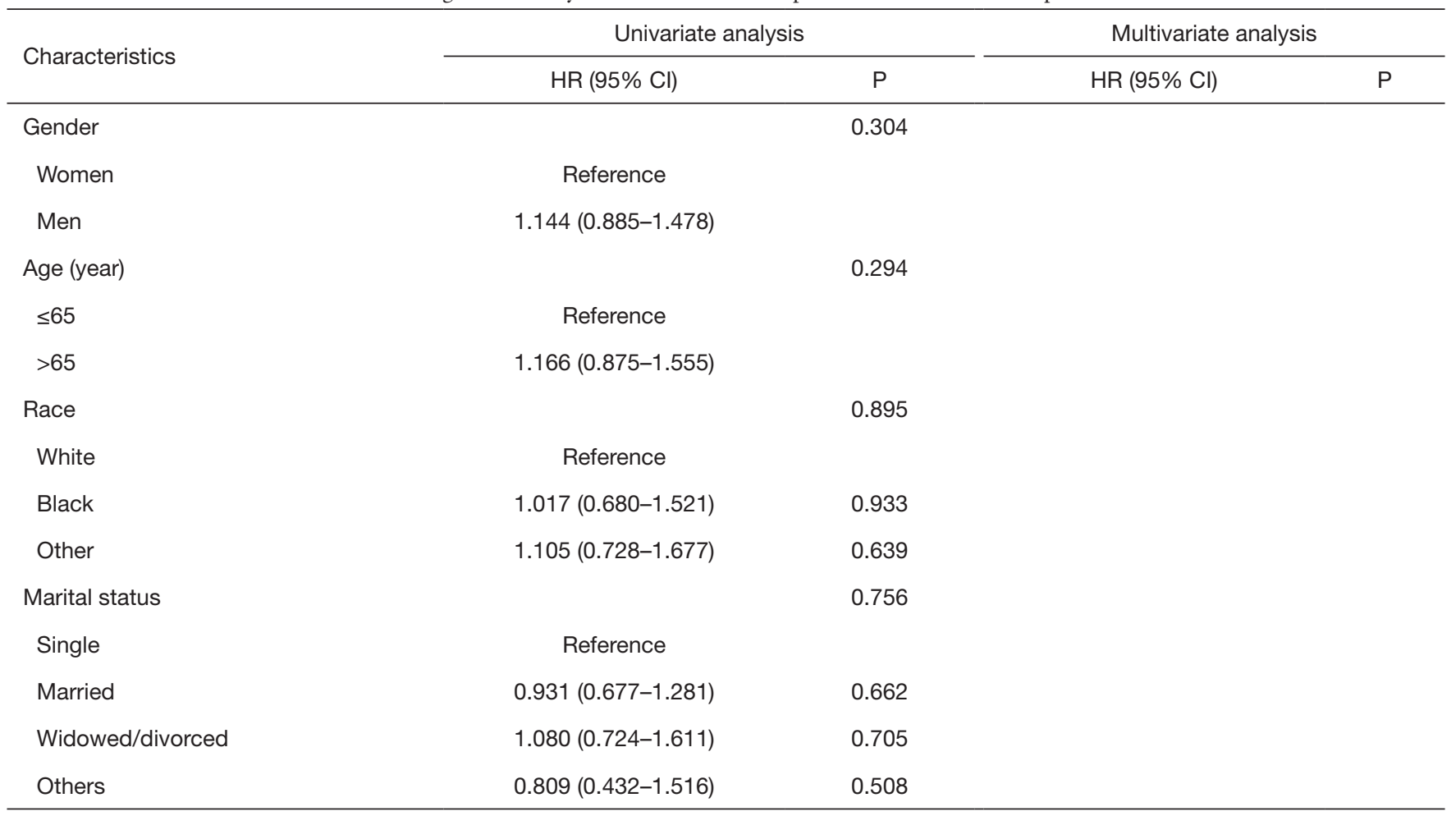

Table 3 (continued) 
Table 3 (continued)

\begin{tabular}{|c|c|c|c|c|}
\hline \multirow{2}{*}{ Characteristics } & \multicolumn{2}{|c|}{ Univariate analysis } & \multicolumn{2}{|c|}{ Multivariate analysis } \\
\hline & $\mathrm{HR}(95 \% \mathrm{Cl})$ & $\mathrm{P}$ & $\mathrm{HR}(95 \% \mathrm{Cl})$ & $\mathrm{P}$ \\
\hline Tumor size $(\mathrm{cm})$ & & 0.719 & & \\
\hline $2-5$ & $0.900(0.546-1.483)$ & 0.678 & & \\
\hline$\geq 5$ & $0.798(0.481-1.324)$ & 0.383 & & \\
\hline CEA & & 0.186 & & \\
\hline+ & Reference & & & \\
\hline- & $0.776(0.563-1.069)$ & 0.120 & & \\
\hline Unknown & $0.807(0.594-1.097)$ & 0.171 & & \\
\hline Unknown & $1.232(0.830-1.828)$ & 0.301 & $1.104(0.743-1.640)$ & 0.624 \\
\hline Perineural invasion & & $<0.001$ & & 0.017 \\
\hline- & Reference & & Reference & \\
\hline+ & $1.681(1.273-2.219)$ & $<0.001$ & 1.465 (1.103-1.946) & 0.008 \\
\hline Unknown & $0.862(0.575-1.292)$ & 0.471 & $0.884(0.589-1.326)$ & 0.551 \\
\hline T status & & 0.098 & & \\
\hline $\mathrm{T} 1$ & Reference & & & \\
\hline $\mathrm{T} 2$ & $0.625(0.199-1.966)$ & 0.422 & & \\
\hline N2 & $2.264(1.627-3.150)$ & $<0.001$ & $2.280(1.625-3.199)$ & $<0.001$ \\
\hline Number of resected LNs $(n=12)$ & & 0.167 & & \\
\hline$<12$ & Reference & & & \\
\hline$\geq 12$ & $0.831(0.639-1.081)$ & & & \\
\hline Number of resected LNs $(n=15)$ & & 0.003 & & $<0.001$ \\
\hline$<15$ & Reference & & Reference & \\
\hline$\geq 15$ & $0.679(0.525-0.878)$ & & $0.619(0.476-0.806)$ & \\
\hline Metastatic location & & 0.460 & & \\
\hline Liver & Reference & & & \\
\hline Lung & $0.904(0.624-1.309)$ & 0.592 & & \\
\hline Liver + lung & $1.455(0.866-2.444)$ & 0.156 & & \\
\hline Others & $1.034(0.761-1.405)$ & 0.830 & & \\
\hline
\end{tabular}


still meaningful and necessary for stage IV rectal cancer patients after receiving preoperative therapy based on the number of resected LNs and $\mathrm{N}$ status. This finding might be important in developing viable treatment strategies for patients of the special group despite the unfactored effect of the missing and incomplete clinicopathologic information of patients that would ultimately affect their survival. Given that only few previous studies have discussed the role of lymphadenectomy on the survival outcome of stage IV rectal cancer patients after receiving preoperative therapy, this study provided baseline information and direction for future research in this area.

Nevertheless, this study was limited by several factors. Data bias was inevitable because of its retrospective nature. The SEER database did not record surgery treatment details which could have influenced survival outcomes. The radiotherapy field design and dose were unknown which might influence disease recurrence. In addition, the sequence between chemotherapy and surgery was unknown in the SEER database thereby might influence the selection of enrolled patients. Cognizant to this, large prospective studies should be conducted in the future to verify these results.

\section{Conclusions}

Indeed, the number of resected LNs is an important independent prognostic factor that influences the survival outcomes of stage IV rectal cancer patients after receiving preoperative therapy. These patients should have 15 or more LNs resected in this study. Nevertheless, large prospective studies should be conducted to further verify the accuracy of this standard.

\section{Acknowledgments}

We thank all staff of the SEER program for the creation of the SEER database.

Funding: None.

\section{Footnote}

Reporting Checklist: The authors present the study in accordance with the STROBE reporting checklist. Available at http://dx.doi.org/10.21037/jgo-20-175

Conflicts of Interest: All authors have completed the ICMJE uniform disclosure form (available at http://dx.doi. org/10.21037/jgo-20-175). The authors have no conflicts of interest to declare.

Ethical Statement: The authors are accountable for all aspects of the work in ensuring that questions related to the accuracy or integrity of any part of the work are appropriately investigated and resolved. The study was conducted in accordance with the Declaration of Helsinki (as revised in 2013). The data in the SEER database were publicly available and de-identified thereby no ethics approval was required.

Open Access Statement: This is an Open Access article distributed in accordance with the Creative Commons Attribution-NonCommercial-NoDerivs 4.0 International License (CC BY-NC-ND 4.0), which permits the noncommercial replication and distribution of the article with the strict proviso that no changes or edits are made and the original work is properly cited (including links to both the formal publication through the relevant DOI and the license). See: https://creativecommons.org/licenses/by-nc-nd/4.0/.

\section{References}

1. Bray F, Ferlay J, Soerjomataram I, et al. Global cancer statistics 2018: GLOBOCAN estimates of incidence and mortality worldwide for 36 cancers in 185 countries. CA Cancer J Clin 2018;68:394-424.

2. Benson AB, Venook AP, Al-Hawary MM, et al. Rectal Cancer, Version 2.2018, NCCN Clinical Practice Guidelines in Oncology. J Natl Compr Canc Netw 2018;16:874-901.

3. Reyngold M, Niland J, ter Veer A, et al. Neoadjuvant radiotherapy use in locally advanced rectal cancer at NCCN member institutions. J Natl Compr Canc Netw 2014;12:235-43.

4. Gunderson LL, Jessup JM, Sargent DJ, et al. Revised tumor and node categorization for rectal cancer based on surveillance, epidemiology, and end results and rectal pooled analysis outcomes. J Clin Oncol 2010;28:256-63.

5. Tepper JE, O'Connell MJ, Niedzwiecki D, et al. Impact of number of nodes retrieved on outcome in patients with rectal cancer. J Clin Oncol 2001;19:157-63.

6. Ha YH, Jeong SY, Lim SB, et al. Influence of preoperative chemoradiotherapy on the number of lymph nodes retrieved in rectal cancer. Ann Surg 2010;252:336-40.

7. Damin DC, Rosito MA, Contu PC, et al. Lymph node retrieval after preoperative chemoradiotherapy for rectal 
cancer. J Gastrointest Surg 2012;16:1573-80.

8. Miller ED, Robb BW, Cummings OW, et al. The effects of preoperative chemoradiotherapy on lymph node sampling in rectal cancer. Dis Colon Rectum 2012;55:1002-7.

9. Gao P, Song Y, Yang Y, et al. What Is the Minimum Number of Examined Lymph Nodes After Neoadjuvant Therapy in Rectal Cancer? J Gastrointest Surg 2018;22:1068-76.

10. Hall MD, Schultheiss TE, Smith DD, et al. Impact of Total Lymph Node Count on Staging and Survival After Neoadjuvant Chemoradiation Therapy for Rectal Cancer. Ann Surg Oncol 2015;22 Suppl 3:S580-7.

11. La Torre M, Lorenzon L, Pilozzi E, et al. Number of harvested lymph nodes is the main prognostic factor in Stage IIa colorectal cancer patients. J Surg Oncol 2012;106:469-74.

12. Joseph NE, Sigurdson ER, Hanlon AL, et al. Accuracy of determining nodal negativity in colorectal cancer on the basis of the number of nodes retrieved on resection. Ann Surg Oncol 2003;10:213-8.

13. Quah HM, Chou JF, Gonen M, et al. Pathologic stage is most prognostic of disease-free survival in locally advanced rectal cancer patients after preoperative chemoradiation. Cancer 2008; 113:57-64.

14. Norwood MG, Sutton AJ, West K, et al. Lymph node retrieval in colorectal cancer resection specimens: national

Cite this article as: $\mathrm{Xi} \mathrm{K}, \mathrm{Yu} \mathrm{H}, \mathrm{Xi} \mathrm{K}$. A retrospective study on the impact of the number of resected lymph nodes on the survival outcome of stage IV rectal cancer patients after preoperative therapy. J Gastrointest Oncol 2020;11(5):870-879. doi: 10.21037/jgo-20-175 standards are achievable, and low numbers are associated with reduced survival. Colorectal Dis 2010;12:304-9.

15. Parsons HM, Tuttle TM, Kuntz KM, et al. Association between lymph node evaluation for colon cancer and node positivity over the past 20 years. JAMA 2011;306:1089-97.

16. Chen SL, Bilchik AJ. More extensive nodal dissection improves survival for stages I to III of colon cancer: a population-based study. Ann Surg 2006;244:602-10.

17. Klos CL, Shellito PC, Rattner DW, et al. The effect of neoadjuvant chemoradiation therapy on the prognostic value of lymph nodes after rectal cancer surgery. Am J Surg 2010;200:440-5.

18. Morcos B, Baker B, Al Masri M, et al. Lymph node yield in rectal cancer surgery: effect of preoperative chemoradiotherapy. Eur J Surg Oncol 2010;36:345-9.

19. Kim J, Huynh R, Abraham I, et al. Number of lymph nodes examined and its impact on colorectal cancer staging. Am Surg 2006;72:902-5.

20. Doll D, Gertler R, Maak M, et al. Reduced lymph node yield in rectal carcinoma specimen after neoadjuvant radiochemotherapy has no prognostic relevance. World J Surg 2009;33:340-7.

21. Baxter NN, Virnig DJ, Rothenberger DA, et al. Lymph node evaluation in colorectal cancer patients: a populationbased study. J Natl Cancer Inst 2005;97:219-25. 